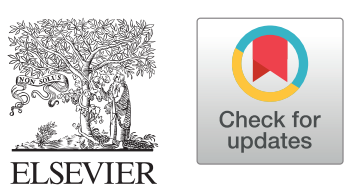

\title{
Review
}

\section{The Canadian Contribution to Science, Techniques, Technology, and Education in Chronic Total Occlusion Percutaneous Coronary Intervention}

\author{
Luiz F. Ybarra, MD, PhD, MBA, ${ }^{a}$ Christopher E. Buller, MD, ${ }^{b}$ and Stéphane Rinfret, MD, SM ${ }^{c}$ \\ ${ }^{a}$ London Health Sciences Centre, Schulich School of Medicine \& Dentistry, Western University, London, Ontario, Canada \\ ${ }^{b}$ Medical Director, Teleflex Inc, Wayne, Pennsylvania, USA \\ ${ }^{c}$ Division of Cardiology, Department of Medicine, McGill University Health Centre, McGill University, Montreal, Quebec, Canada
}

\begin{abstract}
Chronic total occlusions are considered the most complex coronary lesions in interventional cardiology. This article reviews the Canadian clinical and academic contributions to this field, including innovative procedural techniques, teaching and proctoring, clinical research, and the development of novel tools and therapies.
\end{abstract}

Chronic total occlusions (CTOs) have long been considered a barrier to percutaneous revascularization. Nevertheless, early Canadian pioneers, with very limited tools, were active in this field as early as the 1980s. In their steps, subsequent Canadian interventional cardiologists came to occupy an internationally prominent role in the development of techniques and equipment, in CTO percutaneous coronary intervention (PCI) research, and in impactful knowledge translation to a broad audience of learners.

As early as the late 1980s, several centers across the country had already gained substantial experience with balloon angioplasty once Simpson's over-the-wire (OTW) balloon systems became available. With this catheter system, one could easily remove and replace a workhorse guidewire with one with a stiffer tip. At this time, procedures were performed with only antegrade coronary access. Dual access to visualize the distal bed, the current standard approach, started much later. Operators, once they believed they had successfully crossed the occlusion, would use the OTW balloon lumen to

Received for publication July 4, 2020. Accepted September 2, 2020.

Ethics Statement: This manuscript has adhered to the relevant ethical guidelines.

Corresponding author: Dr Stéphane Rinfret, Associate professor of Medicine, McGill University, Director, Interventional Cardiology, McGill University Health Centre, Glen site, 1001 Boulevard Décarie, Montréal, Quebec, H4A 3J1, Canada. Tel.: +1-514-843-1502; fax: +1-514-843-1694.

E-mail: stephane.rinfret@mcgill.ca

See page 24 for disclosure information.

\section{RÉSUMÉ}

L'occlusion totale chronique est considérée comme étant la lésion coronarienne la plus complexe dans le domaine de la cardiologie interventionnelle. Nous passons ici en revue les contributions des cliniciens et des universitaires canadiens dans ce domaine, notamment en matière de techniques d'intervention novatrices, d'enseignement et d'encadrement, de recherche clinique et de mise au point de nouveaux outils et traitements.

inject diluted dye to confirm true lumen position and give additional branching detail not available otherwise. However, this technique often precipitated termination of the procedure when, due to a non-luminal position, contrast was injected into the vessel wall causing hydraulic dissection, or worse, outside the vessel. In spite of this issue, use of monorail systems was considered best practice and thus their use increased, with only minimal improvement in OTW technology.

Although the Canadian success and complication rates were not reported in this era, major limitations were recognized, including the sobering restenosis and re-occlusion rates of the vessel after long successful attempts. Work presented at the 1992 Canadian Cardiovascular Society scientific sessions demonstrated severe recoil and frequent re-occlusion within 24 hours of plain old balloon angioplasty for CTOs. This, and other observational studies, led to the Total Occlusion Study of Canada (TOSCA) trial. The trial assembled experienced PCI operators from across the country and randomized 410 patients after successful crossing of the occlusion to either angioplasty alone or stenting. ${ }^{1,2}$ Only patients with native coronary stenoses accompanied by thrombolysis in myocardial infarction (TIMI) grade 0 or 1 flow in $\geq 3.0 \mathrm{~mm}$-diameter vessels could be recruited. It is important to mention that vessels with TIMI 1 flow would not be considered CTOs according to current definitions. Of 1118 patients screened, only 101 were excluded for inability to cross with a guidewire, which corresponds to quite a high success rate despite the paucity of dedicated equipment at that time. Such good crossing success was likely explained by the experience of the 
operators in the trial but also by the fact that $36 \%$ of the lesions had TIMI 1 flow, with a relatively short median length of $30.5 \mathrm{~mm}$. Stenting (generally requiring multiple PalmazShatz $15-\mathrm{mm}$-length devices) reduced the re-occlusion rate from $20 \%$ to $11 \%$ and target vessel revascularisation from $15.4 \%$ to $8.4 \%$. The binary restenosis rate was reduced from $70 \%$ to $55 \%$. Although the results using multiple firstgeneration bare-metal stents were better than with balloon angioplasty alone, 1 in 10 stented vessels developed reocclusion, and half of the segments had re-stenosis, proportions that were much higher than bare-metal stenting of non-occluded vessels. ${ }^{3,4}$ TOSCA was also the first study to link improvement in ejection fraction to sustained coronary patency.

Drug-eluting stents changed post-PCI results dramatically, ${ }^{5,6}$ typically yielding single-digit re-occlusion rates among vessels with initial treatment success. Neverthless, CTOs remained challenging to cross such that CTO PCI remained unpredictable for years after widespread use of drug-eluting stents. Strauss and collaborators assembled the first Canadian CTO registry, which collected data from close to 15,000 all-comers undergoing coronary angiography from 3 Canadian centers. ${ }^{7}$ His seminal work aimed to document how many of those patients had a CTO present, and how they were managed. In this registry, $18 \%$ of patients had a CTO present, and in the majority of cases, it was managed medically despite the presence of angina in the majority of patients. Of those patients with multivessel disease who were managed with PCI, most CTO segments were not revascularized. When CTO PCI was attempted, the success rate was only $70 \%$ in this highly selected subgroup. As a comparison, the surgeons were able to revascularize $89 \%$ of the CTO vessels. This Canadian study is among the most commonly cited publications in the CTO field, with over 500 citations. Subanalysis from a large surgical trial showed that a coronary artery bypass graft (CABG) causes new CTOs in 20\% of patients, ${ }^{8}$ confirming earlier findings by Bourassa and collaborators.' This phenomenon is likely attributable to competitive flow from the graft and is more common in vessels that had more than $90 \%$ stenoses. ${ }^{8}$ Such a process is not benign, as new CTOs had an adverse impact on outcomes. ${ }^{10}$ The Canadian CTO registry also confirmed a lower CTO prevalence and lower revascularization rates of CTOs by CABG in female compared with male patients. ${ }^{11}$ Animal models for CTOs were also developed, ${ }^{12,13}$ including a calcified preclinical model of CTO, ${ }^{14}$ as well as other alternative treatments (collagenase) with promising effect. ${ }^{15-18}$

Although clinical benefits of CTO PCI were often debated in the 2000s, and frequently used to justify lack of attempts by many operators, Joyal et al. ${ }^{19}$ published the first metaanalysis assessing clinical outcomes of patients with successful vs failed CTO PCI. This work demonstrated a strong and independent association between successful PCI and lower long-term mortality, with similar observations with respect to lower rates of angina and CABG. ${ }^{19}$ This paper has been cited over 400 times in the literature. At the same time, operators were focusing on newer techniques to achieve higher success in a broader spectrum of CTO anatomies. With a focus in facilitating CTO crossing, collagenase was tested in a first-inman pilot study, with good initial results. ${ }^{20}$ Subsequently, the TOSCA- 5 trial tested the impact of collagenase in softening
Table 1. Studies published by Canadian training centers

\begin{tabular}{|c|c|}
\hline Topic & Finding \\
\hline Complexity scores & $\begin{array}{l}\text { First validation of the Japanese-CTO } \\
\text { score in large series }\end{array}$ \\
\hline $\begin{array}{l}\text { Peri-procedural myocardial } \\
\text { infarction }\end{array}$ & $\begin{array}{l}\text { Troponin elevation was quite frequent } \\
\text { and had however no adverse } \\
\text { prognostic significance in the } \\
\text { Quebec cohort. }\end{array}$ \\
\hline Quality of life & $\begin{array}{l}\text { Patients with angina derived the same } \\
\text { benefit irrespective of the complexity } \\
\text { of their CTO, which showed the } \\
\text { importance of being able to master } \\
\text { all techniques for a variety of } \\
\text { patients who benefit from the } \\
\text { procedure irrespective of their } \\
\text { anatomy. }\end{array}$ \\
\hline CTO revascularization & $\begin{array}{l}\text { Infrequent in a large single-center } \\
\text { experience }\end{array}$ \\
\hline Outcomes in different subgroups & $\begin{array}{l}\text { In-stent CTOs, }{ }^{80} \text { post-CABG } \\
\text { CTOs, }{ }^{81} \text { sub-stent } \\
\text { revascularisation, }{ }^{82} \text { post-rotational } \\
\text { atherectomy, }{ }^{83} \text { and using newer } \\
\text { dissection-reentry techniques }\end{array}$ \\
\hline Techniques and approaches & $\begin{array}{l}\text { Use diseased or occluded saphenous } \\
\text { vein graft instead of collaterals to } \\
\text { perform a retrograde approach in } \\
\text { post-CABG patients }{ }^{86} \text {; effectiveness } \\
\text { of the surfing technique to cross } \\
\text { septal collaterals }{ }^{87} \text {; use of sheathless } \\
8 \mathrm{~F} \text { guide catheters through the radial } \\
\text { approach }{ }^{88} \text {; use of drug-eluting } \\
\text { balloon to optimize midterm result } \\
\text { after failed CTO PCI and to help a } \\
\text { subsequent reattempt }\end{array}$ \\
\hline Definition standardization / ARC & $\begin{array}{l}\text { Need for standardized definitions in } \\
\text { the CTO field, leading to the } \\
\text { creation of the international } \\
\text { collaboration CTO-ARC. }\end{array}$ \\
\hline
\end{tabular}

ARC, Academic Research Consortium; CABG, coronary artery bypass graft; CTO, coronary chronic total occlusion; PCI, percutaneous coronary intervention

the proximal cap of CTOs in suitable lesions. Although collagenase did not improve the success rate, lesions were crossed using softer wires. $^{21}$

Following soon after seminal work by Japanese and American pioneers, ${ }^{22}$ the first successful retrograde CTO PCI was performed in Canada in 2010. ${ }^{23}$ With increased interest across Canada in learning new techniques and especially incorporating the trans-radial approach in CTO PCI, several operators started contributing to the early experience through exchange and collegiality. During these years, we witnessed a progressive move from the traditional bifemoral approach to liberal use of the radial-femoral approach, and ultimately biradial access, largely attributable to Canadian advocates. ${ }^{23,24}$ In 2011, the first Canadian antegrade dissection re-entry case using the CrossBoss and StingRay system was performed in Quebec City. This early era gave birth to the so-called hybrid approach, developed in collaboration with US peers, which became the standard of care until now. ${ }^{25,26}$ This approach advocates for a rapid switching between 3 techniques (antegrade wiring, retrograde, and antegrade dissection-re-entry) in order to maximize the success rate of one single procedure, a rate that is now higher than $90 \%$. The long-term safety of subintimal stenting in CTO PCI reassured the community regarding the value of the hybrid approach. ${ }^{27}$ 
New CTO PCI techniques were then developed, such as the balloon-assisted microdissection technique for balloonundilatable lesions, ${ }^{28}$ and move-the-cap techniques for ambiguous proximal CTO cap. ${ }^{29}$ Wijeysundera et al. reported in a cohort of 387 patients from the Canadian CTO registry that CTO territory revascularisation was associated with substantial quality-of-life improvements, one of the few early studies on this important health status metric. ${ }^{30}$ Another study showed that CTO revascularisation (with either CABG or PCI) was associated with improved outcomes in a population-based analysis of 7864 patients in Ontario. In the overall cohort, $29 \%$ of the patients had a CTO, and only $41 \%$ of the CTO patients were revascularized with PCI, highlighting the need for further expansion of the CTO PCI techniques and training. ${ }^{31}$ Combining the experiences from multiple centers, the Canadian CTO PCI registry, which gathered data on CTO PCI short- and long-term outcomes across Canada since 2012, has recently been completed with over 1000 patients. This study answers important questions, especially those related to the sustainability of treatment benefits.

Many Canadian centres also started to offer dedicated CTO PCI training programs, which led to multiple highquality research efforts in different aspects of the CTO PCI field (Table 1).

Furthermore, it is important to mention the Canadian contributions to innovation in tools for CTO PCI. The Progress CTO Guidewire family (Abbott, Santa Clara, CA), as well as the TrapLiner (Teleflex, Wayne, PA), a guide extension catheter with a balloon attached to facilitate equipment exchange, were some of the creations. The Newton system is a technology that suspends the lead apron to reduce muscleskeletal burden on CTO operators. Finally, a new guidewire technology developed by SoundBite Medical, a company from Montreal, which uses "jackhammer-like" energy to ease crossing of CTOs, was first used in a human coronary occlusion in Canada and is now being tested in a large international study.

The CTO PCI field remains dynamic. From an era of dabbling with poorly selected guidewires bent with large radius curves, without contra-lateral guidance, and poor expected (and observed) results, we have successfully moved to an era where up-to-date standardized techniques and approaches are taught, encouraged, and available in most hospitals across the country. Canadian authors have contributed to the rapid expansion of information sources available to learn the hybrid approach, from consensus statements, 32,33 international research collaborations, ${ }^{34-42}$ review articles, ${ }^{43-55}$ editorial comments, ${ }^{26,56-65}$ case series or reports, ${ }^{66-74}$ dedicated textbooks, ${ }^{75}$ and as faculty in large dedicated CTO PCI conferences across the world. All sources of information converge to the same message: mastering all steps of the hybrid approach is key to providing the best results with the lowest complications in patients considered for CTO PCI.

Mirroring specialized practices such as transcatheter aortic valve implantation, CTO PCI has evolved into an interventional cardiology subspecialty of its own. Increasingly, Canadian clinical cardiologists now recognize the role of stateof-the-art CTO PCI in management of symptomatic chronic ischemic heart disease. CTO PCI now offers a predictable, effective, and durable treatment option for patients. The emphasis on collaborative teaching and proctoring that has accompanied technical progress has resulted in CTO PCI availability at most major Canadian interventional programs.

\section{Acknowledgements}

We thank Dr Olga Toleva for her careful review of the manuscript.

\section{Funding Sources}

None.

\section{Disclosures}

L.F.Y. is a consultant for SoundBite Medical, and has received speaker honoraria for Abbott Vascular. C.B. is Medical director, Teleflex. S.R. is a consultant for Boston Scientific, Teleflex, Abbott Vascular, Biotronik, and SoundBite Medical.

\section{References}

1. Dzavik V, Carere RG, Teo KK, et al. An open design, multicentre, randomized trial of percutaneous transluminal coronary angioplasty versus stenting, with a heparin-coated stent, of totally occluded coronary arteries: rationale, trial design and baseline patient characteristics. Total Occlusion Study of Canada (TOSCA) Investigators. Can J Cardiol 1998;14:825-32.

2. Buller CE, Dzavik V, Carere RG, et al. Primary stenting versus balloon angioplasty in occluded coronary arteries: the Total Occlusion Study of Canada (TOSCA). Circulation 1999;100:236-42.

3. Serruys PW, de Jaegere P, Kiemeneij F, et al. A comparison of balloonexpandable-stent implantation with balloon angioplasty in patients with coronary artery disease. Benestent Study Group. N Engl J Med 1994:331:489-95.

4. Fischman DL, Leon MB, Baim DS, et al. A randomized comparison of coronary-stent placement and balloon angioplasty in the treatment of coronary artery disease. Stent Restenosis Study Investigators. N Engl J Med 1994;331:496-501.

5. Suttorp MJ, Laarman GJ, Rahel BM, et al. Primary stenting of totally occluded native coronary arteries II (PRISON II): a randomized comparison of bare metal stent implantation with sirolimus-eluting stent implantation for the treatment of total coronary occlusions. Circulation 2006;114:921-8.

6. Kandzari DE, Rao SV, Moses JW, et al. Clinical and angiographic outcomes with sirolimus-eluting stents in total coronary occlusions: the ACROSS/TOSCA-4 (Approaches to Chronic Occlusions With Sirolimus-Eluting Stents/Total Occlusion Study of Coronary Arteries-4) trial. JACC Cardiovasc Interv 2009;2:97-106.

7. Fefer P, Knudtson ML, Cheema AN, et al. Current perspectives on coronary chronic total occlusions: the Canadian Multicenter Chronic Total Occlusions Registry. J Am Coll Cardiol 2012;59:991-7.

8. Pereg D, Fefer P, Samuel M, et al. Native coronary artery patency after coronary artery bypass surgery. JACC Cardiovasc Interv 2014;7:761-7.

9. Bourassa MG, Lesperance J, Corbara F, Saltiel J, Campeau L. Progression of obstructive coronary artery disease 5 to 7 years after aortocoronary bypass surgery. Circulation 1978;58:I100-6. 
10. Pereg D, Fefer P, Samuel M, et al. Long-term follow-up of coronary artery bypass patients with preoperative and new postoperative native coronary artery chronic total occlusion. Can J Cardiol 2016;32:1326-31.

11. Wolff R, Fefer P, Knudtson ML, et al. Gender differences in the prevalence and treatment of coronary chronic total occlusions. Catheter Cardiovasc Interv 2016;87:1063-70.

12. Jaffe R, Leung G, Munce NR, et al. Natural history of experimental arterial chronic total occlusions. J Am Coll Cardiol 2009;53:1148-58.

13. Fefer P, Robert N, Qiang B, et al. Characterisation of a novel porcine coronary artery CTO model. EuroIntervention 2012;7:1444-52.

14. Osherov AB, Qiang B, Butany J, Wright GA, Strauss BH. A calcified chronic total occlusion preclinical model [e-pub ahead of print]. Catheter Cardiovasc Interv https://doi.org/10.1002/ccd.28870, accessed September 2, 2020.

15. Segev A, Nili N, Qiang B, et al. Human-grade purified collagenase for the treatment of experimental arterial chronic total occlusion. Cardiovasc Revasc Med 2005;6:65-9.

16. Strauss BH, Goldman L, Qiang B, et al. Collagenase plaque digestion for facilitating guide wire crossing in chronic total occlusions. Circulation 2003;108:1259-62.

17. Thind AS, Strauss BH, Karshafian R, et al. The use of ultrasoundstimulated contrast agents as an adjuvant for collagenase therapy in chronic total occlusions. EuroIntervention 2014;10:484-93.

18. Goertz DE, Thind AS, Karshafian R, et al. In vivo feasibility study of ultrasound potentiated collagenase therapy of chronic total occlusions. Ultrasonics 2014;54:20-4.

19. Joyal D, Afilalo J, Rinfret S. Effectiveness of recanalization of chronic total occlusions: a systematic review and meta-analysis. Am Heart J 2010;160:179-87.

20. Strauss BH, Osherov AB, Radhakrishnan $S$, et al. Collagenase total occlusion-1 (CTO-1) trial: a phase I, dose-escalation, safety study. Circulation 2012;125:522-8.

21. Buller CE. TOSCA-5: A prospective, randomized trial evaluating collagenase infusion in patients with coronary artery chronic total occlusions. Presented at: TCT 2016. November 2, 2016; Washington, DC.

22. Thompson CA, Jayne JE, Robb JF, et al. Retrograde techniques and the impact of operator volume on percutaneous intervention for coronary chronic total occlusions an early U.S. experience. JACC Cardiovasc Interv 2009;2:834-42.

23. Rinfret S, Joyal D, Nguyen CM, et al. Retrograde recanalization of chronic total occlusions from the transradial approach; early Canadian experience. Catheter Cardiovasc Interv 2011;78:366-74.

24. Rinfret S, Dautov R. Radial or femoral approach for chronic total occlusion revascularization?: The answer is both. JACC Cardiovasc Interv 2017;10:244-6.

25. Brilakis ES, Grantham JA, Rinfret S, et al. A percutaneous treatment algorithm for crossing coronary chronic total occlusions. JACC Cardiovasc Interv 2012;5:367-79.

26. Rinfret S, Harding SA. A New Japanese CTO algorithm: a step forward or backward? J Am Coll Cardiol 2019;74:2405-9.

27. Rinfret S, Ribeiro HB, Nguyen CM, et al. Dissection and re-entry techniques and longer-term outcomes following successful percutaneous coronary intervention of chronic total occlusion. Am J Cardiol 2014;114: 1354-60.
28. Vo MN, Christopoulos G, Karmpaliotis D, et al. Balloon-assisted microdissection "BAM" technique for balloon-uncrossable chronic total occlusions. J Invasive Cardiol 2016;28:E37-41.

29. Vo MN, Karmpaliotis D, Brilakis ES. "Move the cap" technique for ambiguous or impenetrable proximal cap of coronary total occlusion. Catheter Cardiovasc Interv 2016;87:742-8.

30. Wijeysundera HC, Norris C, Fefer P, et al. Relationship between initial treatment strategy and quality of life in patients with coronary chronic total occlusions. EuroIntervention 2014;9:1165-72.

31. Shuvy M, Qiu F, Chee ATA, et al. Management of chronic total coronary occlusion in stable ischemic heart disease by percutaneous coronary intervention versus coronary artery bypass grafting versus medical therapy. Am J Cardiol 2017;120:759-64.

32. Galassi AR, Brilakis ES, Boukhris M, et al. Appropriateness of percutaneous revascularization of coronary chronic total occlusions: an overview. Eur Heart J 2016;37:2692-700.

33. Brilakis ES, Mashayekhi K, Tsuchikane E, et al. Guiding principles for chronic total occlusion percutaneous coronary intervention. Circulation 2019;140:420-33.

34. Christakopoulos GE, Christopoulos G, Carlino M, et al. Meta-analysis of clinical outcomes of patients who underwent percutaneous coronary interventions for chronic total occlusions. Am J Cardiol 2015;115: 1367-75.

35. Azzalini L, Giustino G, Ojeda S, et al. Procedural and long-term outcomes of bioresorbable scaffolds versus drug-eluting stents in chronic total occlusions: the BONITO Registry (bioresorbable scaffolds versus drug-eluting stents in chronic total occlusions). Circ Cardiovasc Interv 2016;9:e004284.

36. Christopoulos G, Kotsia AP, Rangan BV, et al. "Subintimal external crush" technique for a "balloon uncrossable" chronic total occlusion. Cardiovasc Revasc Med 2017;18:63-5.

37. Ellis SG, Burke MN, Murad MB, et al. Predictors of successful hybridapproach chronic total coronary artery occlusion stenting: an improved model with novel correlates. JACC Cardiovasc Interv 2017;10:1089-98.

38. Patel SM, Menon RV, Burke MN, et al. Current perspectives and practices on chronic total occlusion percutaneous coronary interventions. J Invasive Cardiol 2018;30:43-50.

39. Karatasakis A, Danek BA, Karacsonyi J, et al. Mid-term outcomes of chronic total occlusion percutaneous coronary intervention with subadventitial vs. intraplaque crossing: a systematic review and metaanalysis. Int J Cardiol 2018;253:29-34.

40. Megaly M, Ali A, Saad M, et al. Outcomes with retrograde versus antegrade chronic total occlusion revascularization [e-pub ahead of print]. Catheter Cardiovasc Interv https://doi.org/10.1002/ccd.28616, accessed September 2, 2020.

41. Megaly M, Karatasakis A, Abraham B, et al. Radial versus femoral access in chronic total occlusion percutaneous coronary intervention. Circ Cardiovasc Interv 2019;12:e007778.

42. Xenogiannis I, Gkargkoulas F, Karmpaliotis D, et al. Retrograde chronic total occlusion percutaneous coronary intervention via saphenous vein graft. JACC Cardiovasc Interv 2020;13:517-26.

43. Strauss BH, Segev A, Wright GA, et al. Microvessels in chronic total occlusions: pathways for successful guidewire crossing? J Interv Cardiol 2005; 18:425-36.

44. Fefer P, Carlino M, Strauss BH. Intraplaque therapies for facilitating percutaneous recanalization of chronic total occlusions. Can J Cardiol 2010;26(suppl A). 32a-6a. 
45. Bagur R, Rinfret S. Transradial approach for chronic total occlusion percutaneous coronary intervention. Interv Cardiol Clin 2012;1:355-63.

46. Joyal D, Thompson CA, Grantham JA, Buller CE, Rinfret S. The retrograde technique for recanalization of chronic total occlusions: a stepby-step approach. JACC Cardiovasc Interven 2012;5:1-11.

47. Strauss BH, Shuvy M, Wijeysundera HC. Revascularization of chronic total occlusions: time to reconsider? J Am Coll Cardiol 2014;64:1281-9.

48. Vo MN, Brilakis ES, Kass M, Ravandi A. Physiologic significance of coronary collaterals in chronic total occlusions. Can J Physiol Pharmacol 2015;93:867-71.

49. Azzalini L, Vo M, Dens J, Agostoni P. Myths to debunk to improve management, referral, and outcomes in patients with chronic total occlusion of an epicardial coronary artery. Am J Cardiol 2015;116: 1774-80.

50. Rinfret S, Joyal D, Spratt JC, Buller CE. Chronic total occlusion percutaneous coronary intervention case selection and techniques for the antegrade-only operator. Cath Cardiovasc Interv 2015;85:408-15.

51. Brilakis ES, Karmpaliotis D, Vo MN, et al. Update on coronary chronic total occlusion percutaneous coronary intervention. Interv Cardiol Clin 2016;5:177-86.

52. Sathananthan J, Dzavik V. Coronary intervention for chronic total occlusion: current indications and future directions. Coron Artery Dis 2017;28:426-36.

53. Karatasakis A, Danek BA, Karmpaliotis D, et al. Approach to CTO intervention: overview of techniques. Curr Treat Options Cardiovasc Med 2017;19:1.

54. Azzalini L, Carlino M, Brilakis ES, et al. Subadventitial techniques for chronic total occlusion percutaneous coronary intervention: the concept of "vessel architecture.". Cath Cardiovasc Interv 2018;91:725-34.

55. Strauss BH, Elbaz-Greener G. Strategies for balloon-uncrossable chronic total occlusion lesions. Cardiovasc Revasc Med 2018;19:816-7.

56. Vo M, Brilakis ES. Faster, easier, safer: "guideliner reverse CART" for retrograde chronic total occlusion interventions. Cath Cardiovasc Interv 2014;83:933-5.

57. Shuvy M, Strauss BH. The mini-STAR technique in chronic total occlusions: maximizing the interventional toolbox. Can J Cardiol 2014;30:1253-5.

58. Arbel Y, Strauss BH. Mortality benefits with CTO PCI: moving the goalpost closer. Eur Heart J 2015;36:3199-201.

59. Elbaz-Greener G, Wijeysundera HC. Coronary chronic total occlusions: time to abandon a culture of therapeutic nihilism? Circ Cardiovasc Qual Outcomes 2017;10:e004295.

60. Ybarra LF, Rinfret S. Third-generation drug-eluting stents: Can they be used in chronic total occlusions? Coron Artery Dis 2017;28:366-8.

61. Potter BJ, Matteau A, Noiseux N, Mansour S. High stakes: CTO-PCI in the post-CABG patient. Can J Cardiol 2018;34:238-40.

62. Elbaz-Greener G, Strauss BH. Coronary intervention for chronic total occlusions: What should the guidelines say? Coron Artery Dis 2018;29: 279-82.

63. Rinfret S, Ybarra LF. Antegrade chronic total occlusion crossing: crossboss first or last? JACC Cardiovasc Interv 2018;11:234-6.

64. Rinfret S. A heartbreaking sadness: Does percutaneous coronary intervention breathe new life into the health status of patients with chronic total occlusion? JACC Cardiovasc Interven 2019;12:659-61.
65. Rinfret S, Dautov R. When SVGs "had enough": using them as retrograde conduits to resurrect native coronary arteries. JACC Cardiovasc Interv 2020;13:527-9.

66. Erlich I, Strauss BH, Butany J. Stent thrombosis following the STAR technique in a complex RCA chronic total occlusion. Cath Cardiovasc Interv 2006;68:708-12.

67. Bagur R, Bernier M, Kandzari DE, et al. A novel application of contrast echocardiography to exclude active coronary perforation bleeding in patients with pericardial effusion. Cathi Cardiovasc Interv 2013;82: 221-9.

68. Vo MN, Ravandi A, Brilakis ES. "Tip-in" technique for retrograde chronic total occlusion revascularization. J Invasive Cardiol 2015;27: E62-4.

69. Dautov R, Abdul Jawad Altisent O, Rinfret S. Stumpless chronic total occlusion with no retrograde option: multidetector computed tomography-guided intervention via bi-radial approach utilizing bioresorbable vascular scaffold. Cath Cardiovasc Interv 2015;86:E258-62.

70. Abdel-Karim AR, Vo M, Main ML, Grantham JA. Interventricular septal hematoma and coronary-ventricular fistula: a complication of retrograde chronic total occlusion intervention. Case Rep Cardiol 2016;2016: 8750603 .

71. Dautov R, Nguyen CM, Rinfret S. Stent luxation: possible complication of subadventitial stenting in coronary chronic total occlusion revascularization. Cath Cardiovasc Interv 2017;89:872-5.

72. Elbaz-Greener G, Wijeysundera HC. A presentation of postcardiac injury syndrome after successful chronic total occlusion percutaneous coronary intervention using dissection re-entry techniques. Clin Case Rep 2017;5: 855-8.

73. Vo MN, Brilakis ES, Grantham JA. Novel use of cutting balloon to treat subintimal hematomas during chronic total occlusion interventions. Cath Cardiovasc Interv 2018;91:53-6.

74. Doshi D, Hatem R, Masoumi A, Karmapaliotis D. A case report of right ventricular compression from a septal haematoma during retrograde coronary intervention to a chronic total occlusion. Eur Heart J Case Rep 2019;3:ytz089.

75. Rinfret S, ed. Percutaneous Intervention for Coronary Chronic Total Occlusion. The Hybrid Approach. 1st ed. London: Springer-Verlag, 2016.

76. Nombela-Franco L, Urena M, Jerez-Valero M, et al. Validation of the Jchronic total occlusion score for chronic total occlusion percutaneous coronary intervention in an independent contemporary cohort. Circ Cardiovasc Interv 2013;6:635-43.

77. Dautov R, Ybarra LF, Nguyen CM, et al. Incidence, predictors and longer-term impact of troponin elevation following hybrid chronic total occlusion percutaneous coronary intervention. Cath Cardiovasc Interv 2018;92:E308-16.

78. Ybarra LF, Dautov R, Gibrat C, Dandona S, Rinfret S. Midterm anginarelated quality of life benefits after percutaneous coronary intervention of chronic total occlusions. Can J Cardiol 2017;33:1668-74.

79. Azzalini L, Jolicoeur EM, Pighi M, et al. Epidemiology, management strategies, and outcomes of patients with chronic total coronary occlusion. Am J Cardiol 2016;118:1128-35.

80. Azzalini L, Dautov R, Ojeda S, et al. Procedural and long-term outcomes of percutaneous coronary intervention for in-stent chronic total occlusion. JACC Cardiovasc Interv 2017;10:892-902.

81. Azzalini L, Ojeda S, Karatasakis A, et al. Long-term outcomes of percutaneous coronary intervention for chronic total occlusion in patients 
who have undergone coronary artery bypass grafting vs those who have not. Can J Cardiol 2018;34:310-8.

82. Azzalini L, Karatasakis A, Spratt JC, et al. Subadventitial stenting around occluded stents: a bailout technique to recanalize in-stent chronic total occlusions. Catheter Cardiovasc Interv 2018;92:466-76.

83. Azzalini L, Dautov R, Ojeda S, et al. Long-term outcomes of rotational atherectomy for the percutaneous treatment of chronic total occlusions. Catheter Cardiovasc Interv 2017;89:820-8.

84. Azzalini L, Dautov R, Brilakis ES, et al. Impact of crossing strategy on midterm outcomes following percutaneous revascularisation of coronary chronic total occlusions. EuroIntervention 2017;13:978-85.

85. Azzalini L, Dautov R, Brilakis ES, et al. Procedural and longer-term outcomes of wire- versus device-based antegrade dissection and re-entry techniques for the percutaneous revascularization of coronary chronic total occlusions. Int J Cardiol 2017;231:78-83.

86. Dautov R, Manh Nguyen C, Altisent O, Gibrat C, Rinfret S. Recanalization of chronic total occlusions in patients with previous coronary bypass surgery and consideration of retrograde access via saphenous vein grafts. Circ Cardiovasc Interv 2016;9:e003515.

87. Dautov R, Urena M, Nguyen CM, Gibrat C, Rinfret S. Safety and effectiveness of the surfing technique to cross septal collateral channels during retrograde chronic total occlusion percutaneous coronary intervention. EuroIntervention 2017;12:e1859-67.

88. Dautov R, Ribeiro HB, Abdul-Jawad Altisent O, et al. Effectiveness and safety of the transradial $8 \mathrm{Fr}$ sheathless approach for revascularization of chronic total occlusions. Am J Cardiol 2016;118:785-9.

89. Ybarra LF, Dandona S, Daneault B, Rinfret S. Drug-coated balloon after subintimal plaque modification in failed coronary chronic total occlusion percutaneous coronary intervention: a novel concept. Catheter Cardiovasc Interv 2020;96:609-13.

90. Ybarra LF, Piazza N, Brilakis E, et al. Clinical endpoints and key data elements in percutaneous coronary intervention of coronary chronic total occlusion studies: a call to the academic research consortium for standardized definitions. JACC Cardiovasc Interv 2017;10:2185-7. 